\title{
FACTORS LIMITING SEED GERMINATION IN Scyphiphora hydrophyllacea GAERTN f. AND Pemphis acidula J R \& FORST
}

\author{
P L Hettiarachchi \& RK Jayaratne \\ Department of Botany, University of Sri Jayewardenepura
}

Scyphiphora hydrophyllacea is a highly threatened true mangrove confined to Jaffna and a single locality in Kalpitiya (Trimen 1974; Dassanayake and Clayton 1998). Pemphis acidula is restricted to small pockets in fow coastal areas. Both produce fruits and seeds nevertheless, seedlings were not observed in their natural habitats. Factors governing sced germination in these two species were studied. For all experiments, randomly collected ripe seed samples were used within two weeks of collection. Moist filter paper method was used and daily observations were recorded.

In P. acidula, sced production was $100 \%$. Pcrcentage of fruit bearing secds was $10 \%$ in S. hydrophyllacea, but none of them gave rise to healthy seedlings. Seed germination of both species was $0 \%$ in water collected from respective natural habitats. In P. acidula $\%$ germination was $35 \%$ in $75 \%$ and $40 \%$ in $87.5 \%$ dilution of water from natural habitat. In distilled water, $65 \%$ of the seeds germinated. Continuous washing of sceds in running tap water increased percentage germination to $75 \%$.

Dormancy breaking treatments such as heat treatment, sced nicking, acid base treatment, cold treatment and treatment with gibbereliic acid did not increase germination above normal $65 \%$ value.

Exposure to natural light, photoperiod and oxygen level also affected secd germination. Analysis of data consisted of ANOVA at $5 \%$ level of significance using Minitab package. In $P$. acidula, salinity of soil water (up to $34 \mathrm{ppt}$ ) and salt deposits on secd coat seem to be major causes hindering seed germination in natural habitat. Sceds buricd in sand may also not reccive adequate amount of light (Isikava 1962; Fujii 1962). Oxygen concentration may not be enough when the ground is covered with water during tides. Lack of secdlings may therefore be due to lack of sced germination under natural conditions.

In S. hydrophyllacea, very low percentage of sced bearing fruits and inability to produce healthy seedlings explain why it has become highly threatened. Production of large number of scedless fruits and inability to produce normal seedlings could be due to genetic disorder in seeds, which is a very common phenomenon known as inbreeding depression in isolated, small populations.

Presence of self-sterility and the absence of pollinator might be some other reasons. Hence, studies on the possibility of propagating $\mathrm{S}$. hydrophyllacea by vegctative means are urgently needed to conserve this highly threatened trec specics.

Proceedings of the Eighth Annual Forestry and Environment Symposium 2002 of the Department of Forestry and Environmental Science, University of Sri Jayewardenepura, Sri Lanka 